ASSESSMENT OF CRANULOCYIE VIABIL.ITY AND NBT REDUCTION TEST RESULTS IN CHILDREN LIVING IN AN AREA POLLUIED BY HEAVY METALS

89

Francjszek Śliwa, Aldona Lukas, Wj.told l.ukas

Clinic of Pedjatry and Hematology Silesjan Medjcal Academy 41-800 Zabrze, Poland

Granulocyte Viability /G.V.T/ and the Nitro-blue-Tetrazoljum reduction test /NBT RT/were evaluated in 258 children living in the area of Zijnc Sinelting Works, Miasteczko Sląskie/Katowice District/ polluted very strongly by heavy metals / Pb, Zn, Cd/. G.V.T. was determined by Cocchi and al. and NBT RT by Raman and al. method. An increase in the percentage of dead granulocytos and a decrease in the value of NBT RT were found, particularly in the youngest children. A large number of examjned children showed an elevated $\mathrm{Pb}$ and decreased $\mathrm{Zn}$ and $\mathrm{Mg}$ levels in blood. A correlation was found between $\mathrm{Mg}$ and granulocyte vjabjlity $/ t=-3,011$, $\rho<0,05 /$, as well as between $Z n$ and NBT RT values $/ t=4,434$ $\mathrm{p}<0,0.5 \%$. The results of investigations conf $i \mathrm{rm}$ the negative jnfluence of heavy metals polluted environnent on intracellulat metabolic processes in granulocytes. This phenomenon is highly intensified $\mathrm{in}$ the youngest children. The unfavourable $\mathrm{Pt}$ influence on children's jumiunity may be also caused by the interaction of $\mathrm{Pb}$ with $\mathrm{Mg}$ and $\mathrm{Zn}$ in the process of absorption in the intestinal tract.

MEASURED FINAL HEIGHT AND TARGET HEIGHT IN BOYS WITH CONSTITUTIONAL GROWTH DELAY

90 Michael Sperlich, Otfrid Butenandt, Ursula Kuhnle and Hans Peter Schwarz

University Children's Hospital, D-8000 Munich, Germany

There is considerable dispute as to whether boys with constitutional growth delay (CGD) do reach their target height (mid-parental height + $6.5 \mathrm{~cm}$ ). To answer this question, patients with short stature and CGD seen at our institution within the last 15 years are being restudied. So far, 20 adult males have been seen and their height has been measured by stadiometer. At the initial presentation, chronological age was $14.0 \pm 1.6(\mathrm{SD}) \mathrm{yr}$, bone age $11.4 \pm 1.7 \mathrm{yr}$, height $147.4 \pm 7.1 \mathrm{~cm}$, testicular volume $5.6 \pm 3.7 \mathrm{~mL}$. A positive family history with late menarche $>14 \mathrm{yr}$ in the mother and/or continued fast growth $>16 \mathrm{yr}$ in the father could be elicited in $18 / 20$ patients. When restudied, chronological age was $22.7 \pm 1.7 \mathrm{yr}(20.2-26.9)$, testicular volume $23.0 \pm 4.3 \mathrm{~mL}$, final height $171.9 \pm 5.2 \mathrm{~cm}$. This height was very close to the self-estimate of the patients $(171.8 \pm 5.5 \mathrm{~cm})$. Moreover, it was not significantly different from the target height of $173.1 \pm 4.3 \mathrm{~cm}$ and from the initial Bayley-Pinneau prediction of $172.2 \pm 6.7 \mathrm{~cm}$ (paired t-test). We conclude that on the average our patients with CGD did reach their full height potential and Bayley-Pinneau predictions were useful.

MATERNAL PHENYLKETONURIA (MPKU) - DISEASE SPECIFIC KNOWLEDGE OF FEMALE PATIENTS

91 B. Fünders, J. Weglage, K. Ulirich Dept. of Pediatrics, Univ. of Münster, FRG

68 patients, 30 with classical PKU and 38 with persistent hyperphenylalaninemia (HPA) were interviewed about their knowledge concerning MPKU. Mean age was $23+4 \mathrm{y}$. All patients had not contacted a metabolic unit for at least $10 \mathrm{y}$.

Mean IQ (Hawie) in PKU patients was $93+7$ in IIPA $106+5$. Only $15 \%$ of the patients knew that their children could be affected by elevated maternal phelevels; none could specify the Phe-toxicity on their levels; none could specify the Phe-toxicity on their
offsprings. 85 \% of patients for example believed that their children would have PKU. Knowledge of $\mathrm{PKU}$ and HPA patients did not differ significantly. The poor knowledge of patients at risk for MPKU demands for a systematic medical and social care to guarantee successful treatment in the future. This guarantee successful treatment in the future. This of the patients with classical PKU were not convinced of the need for dietary treatment during pregnancy.
CANCER FREQUENCY IN THE REGION OF GOMIEL AFTER THE NUCLEAR PLANT ACCIDENT OF CHERNOBYL.

92 M. Andolina, M. Cuttini, A, de Manzini, V.v. Yuchnel. Istituto per I' Infanzia, Trieste, Italy; Dept. of Health, BSSR, USSR.

Since the Chernobyl nuclear disaster about 1.6 million people in the area of Gomiel (Southern Byelorussia) have been exposed to most of the radioactive pollution derived from the plant.

Starting already with 1986, the frequency of malignant tumors showed a steady increase: from 223.7 to $246.3 / 100000$ in 1990 Cancer mortality was $141.9 / 100000$ in ' 86 and 159.3 in '90. Incidence of thyroid tumors rose from 3.1 in ' 86 to $4.1 / 100000$ in ' 90 , but in the same period also diagnosis of endemic goiter increased threefold. Frequency of acute leukemia was $1.4 / 100000$ in ' 85 and 2.0 in 190 , but also that of chronic lymphoid leukemia increased from 2.7 to $4.4 / 100000$ in the same years. Frequency of chronic myeloid leukemia and of multiple myeloma showed only slight variations. The induction period after radioactive contamination is said to be 2-5 years for thyroid carcinoma and leukenias. The early increase of cancer diagnosis in the area of Gomiel, therefore, may in part be the effect of increased clinical attention and improved health services after the nuclear accident.

MUNICH ASTHMA- AND ALLERGY SURVEY. IS ASTHMA BEING UNDERDIAGNOSED ?

93 Erika von Mutius ${ }^{1}$, Eva Stiepel ${ }^{2}$, Peter Reitmeir ${ }^{2}$, Thomas Nicolai ${ }^{1}$ - Department of Pediatrics, University of Munich, D-8000 München 2, Germany. ${ }^{2}$ Medis-Institut, GSF, D-8042 Neuherberg, Germany.

There is evidence that morbidity and mortality from asthma as well as the prevalence of allergic diseases is increasing. As data were missing in Germany, we studied in a crossectional design 9403 schoolchildren (age 9-11 years) in an urban and rural area of Bavaria using a (age 9-11 years) in an urban and rural area of Bavaria using a
questionnaire, skin prick tests and pulmonary function tests before and questionnaire, skin prick tests and pulmonary function tests before and
after cold air challenge. The responserates were: $87 \%$ for questionnaires, $77 \%$ for allergy or pulmonary function tests. Evaluation of the questionnaires gave the following prevalences: $18,1 \%$ allergic rhinitis, $19,7 \%$ atopic dermatitis, $2,5 \%$ asthma and $5,5 \%$ recurrent wheezy bronchitis.Beyond this $8,3 \%$ had recurrent wheezing and $3,4 \%$ chronic cough by night or exercise without any diagnose of asthma or wheezy bronchitis. $42 \%$ of all german children are atopic, ie exhibit at least one positive prick test reaction for the six aeroallergens at least one positive prick test reaction for the six aeroallergens
tested.Bronchial hyperreactivity was found in $9 \%$ of german children. Atopic diseases and asthma are more frequent in the urban than the rural area. In summary there is an important underdiagnosis of asthma in this pediatric population.

\section{CARDIOVASCULAR RISK FACTORS IN CHILDHOOD} OBESITY.

94 K. Zwiauer. Renate Pakosta.and K. Widhalm. Department of Pedlatics, University of Venna Medlcal Schod, A-1090 Venna, AUSTRIA.

Obesity is a major risk factor for atherosclerotic dlseases. In adults. The purpose of the study wos to Investlgate cardlovascular risk foctors in childhood obesity and assoclations of risk factors with different measuzes of obesity, body composithon and fat distribution.

105 grossty obese children and adolescents ( 64 female and 41 male. meantSD 105 grossty obese children and adolescents ( 64 female and 41 male. meantsD an overnight fast and blood liplds (enzymatically), lipoproteins (polyanionoreclpltation) an ovemight fast and blood liplds (enzymatically), lipoproteins (polyantonpreclpltation) and apolipoproteins (RID), glucose, and insulln were determined. Systollic (SBP) and diastollc blood pressure (DBP) were measured after a $15 \mathrm{mln}$ rest dupllcate, body composition with body impedance onalysls (BIA 109. AKERN/RJL). Walst and hip measured for calculation of walst-hip-ratio WHR).

\begin{tabular}{|c|c|c|c|c|c|c|}
\hline \multicolumn{4}{|c|}{ Partial cortelation coeffici } & \multicolumn{3}{|c|}{ (corrected for age and sex) } \\
\hline & & DBP & TG & HDL-C & LDL-C & Insulin \\
\hline & & 0.47 & 0.113 & & & \\
\hline$M$ & & 0.48 & 0.1 & 0.13 & & \\
\hline HR & $0.537 \cdots$ & $0.489 \cdot \cdot$ & $0.348+$ & $\begin{array}{r}0.372+ \\
+p=0\end{array}$ & $\begin{array}{c}0.32\}+ \\
50<0.01\end{array}$ & 0.53 \\
\hline
\end{tabular}

SBP and DBP in the obese children and odolescents were closely related to percentual overwelght, BMI and WHR, too. Iriglycerldes (TG). HDL-C. LDL-C and insultin showed no correlation with any of the measurments of adlposity. However. these parameters were assoclated with the body fot distribution. Independentiy from the degree of adlposity. We therefor conclude that WHR Is a better indicator for cardiovascular risk factors in obese children compared to percent overweight or BMl. 